\title{
¿Y LA INDEPENDENCIA NOS HIZO POBRES? ESTADO Y NUEVA FISCALIDAD. PERÚ (1821-1827) ${ }^{1}$
}

\author{
Did independence make us poor? \\ The State and the new fiscal system. Peru (1821-1827) \\ Dionisio de Haro
Universidad Rey Juan Carlos, España
}

Resumen: En el período comprendido entre 1821 y 1827 se inició en el Perú el proceso de transformación consistente en la transición de un sistema hacendístico colonial a otro moderno. Con la guerra y la independencia se abrió un tiempo de aprendizaje y reformas en el que, con el objetivo de dotar al nuevo Estado de una Hacienda con suficiencia recaudatoria, se pretendió reorganizar el sistema y ensanchar la base fiscal. El presente trabajo analiza el alcance y los límites de un proyecto central para entender al Perú de la primera mitad del siglo XIX, estableciendo nexos que enlazan la evolución económica y los hechos políticos.

Palabras clave: independencia del Perú, impuestos, Hacienda pública, virreinato, nación.

\begin{abstract}
A process of transformation began in Peru between 1821 and 1827. This consisted of a transition from a colonial tax system to a modern one. War and independence led to a period of learning and reforms with the aim of providing the new State with a robust finance system supported by adequate levels of collected funds to reorganize the system and widen the fiscal base. This work analyses the scope and limits of a central project to understand Peru in the first half of the 19th century, establishing links between economic developments and political facts.
\end{abstract}

Keywords: independence of Peru, taxes, public estate, viceroyalty, nation.

1. El presente artículo forma parte del proyecto $I+D+i$ «Reformas institucionales en Hispanoamérica, siglo XIX. Actores/agentes y publicidad en su socialización pública» (PID2020-113099GB-I00), financiado por el Ministerio de Ciencia e Innovación. 


\section{Introducción}

El tema de la Hacienda o, mejor, de las Haciendas ha sido merecedor en los últimos tiempos de una atención especial por parte de la historia. La materia, que cuenta con una consolidada y prestigiosa tradición con obras de amplio espectro, ha ampliado sus objetivos poniendo el acento en las repercusiones económicas, sociales e institucionales de la presión fiscal. ${ }^{2}$ La relación entre fiscalidad, configuración institucional y actores sociales se ha revelado como una perspectiva de investigación fértil para analizar las dinámicas en el pasado. De hecho, los mecanismos de captación de fondos, el volumen y el destino de las finanzas públicas pueden ser tenidos como la expresión de equilibrios y acuerdos, resistencias y conflictos, tanto explícitos como implícitos, en los que se conjuga lo social, lo político, lo económico e incluso lo cultural. En este marco, el presente trabajo trata de avanzar en la concepción de la fiscalidad como elemento modular en la formación del espacio nacional que permite incidir sobre las continuidades y las rupturas en las dinámicas sociales y políticas, y el desenvolvimiento económico. Al considerar estas cuestiones, la experiencia del Perú durante la guerra de la Independencia y en los años inmediatamente posteriores representa un caso icónico. El colapso del modelo virreinal, la insoslayable transición hacia un marco nuevo, poniendo el énfasis en la siempre nerviosa relación entre política y hacienda, y su influyente impacto en la trayectoria económica y social lo convierten en un laboratorio idóneo en el que analizar el complejo proceso de construcción del Estado y reorganización de la Hacienda. Un camino que no fue sencillo.

A pesar de la creciente luminosidad con que aparentemente asistimos al período de la guerra de la Independencia en el Perú (1821-1824), seguimos pendientes de un relato preciso e integrador en torno a la historia económica del momento. Los años comprendidos entre la emancipación y mediados del siglo XIX representan un tiempo económico aún poco conocido y con obstáculos difíciles de sortear cuando a la tortuosa tarea de reconstrucción de la administración central le acompañó un largo silencio estadístico (Rojas, 2019). Una época vidriosa en la que, una vez liquidada la dependencia con respecto a España, el desarrollo económico e institucional no fue el esperado. Las razones aún no están del todo claras. O bien todo había formado parte de una retórica hueca e imprecisa en torno a un intenso drenaje de una colonia «rica» por parte de una metrópoli quebrada, o bien la guerra descuadró la economía hasta el punto de privarla de un mínimo pulso que fuese capaz de transformar los viejos «excedentes» en capital productivo. La primera opción nos llevaría a preguntarnos, parafraseando a Francisco de Quevedo, cómo es que, a pesar de disponer de la «plata», tras la Independencia los niveles de renta per cápita se contrajeron (Selden Rose, 1916: 178). Sin embargo, las investigaciones han tendido a prestar más atención a la segunda opción, pero dejando cabos aún por atar (Contreras, 2010 y 2012).

2. Fisher (2000); Hamnett (2000); Espina Montero (2001); Contreras (2002); Anna (2003); Brown (2008); Irigoin y Grafe (2008); Summerhill (2008); Flores Guzmán (2010); Tepaske y Brown (2010); Salinas (2011); Kuethe y Andrien (2014); Irigoin (2016); Haro (2019). 
Los problemas económicos se mantuvieron plenamente vigentes, e incluso algunos de ellos se agudizaron tras la guerra. $Y$ aunque, desde el punto de vista de los precios, el país todavía se encontraba a finales de la última fase alcista posbélica, el resto de los indicadores no manifestaron la tónica esperada. Las autoridades, que fueron incapaces de garantizar unos fondos públicos estables y suficientes, estrecharon de forma acelerada, y en ausencia de los precisos mecanismos de control, sus dependencias con respecto a los capitales extranjeros. Con objeto de financiar las reformas y conseguir un mínimo nivel de liquidez, y tras constatar el agotamiento del crédito nacional, se recurrió a la consecución de empréstitos exteriores con los que lograr un sostén presupuestario mínimo mientras las reformas testaban su potencial (Palacios Moreyra, 1983).

Tras la etapa de desconcierto en la hacienda que representó el Protectorado y los deshilachados semestres que le siguieron (Haro, 2014), las iniciativas fiscales del trienio 1824-1827 pretendieron fijar un marco de estabilidad sobre el cual manejar con suficiencia las finanzas públicas del nuevo Estado. Primero Hipólito Unanue, en la etapa de San Martín, y luego, ya con la guerra finalizada, José de Larrea y Loredo y José María de Pando, a los que se uniría el propio Unanue, ya con una visión más completa y precisa en torno a las controversias fiscales, propusieron desde el ámbito de sus competencias iniciativas, arbitrios y resoluciones que aspiraron a conformar un paquete de reformas que debían traducirse en un punto de inflexión. Entonces fueron desplegadas las líneas maestras. En espera de un rebote en el crecimiento económico, resultado natural del final de la guerra, junto con la elaboración del primer presupuesto y unido a la esperada recuperación de la tributación, las previsiones apuntaban a un alza sostenida de los ingresos que permitiese recuperar un sistema drenado. Asimismo, la reorganización del Ministerio de Hacienda trató de ayudar al nuevo Estado a dejar atrás la ligereza administrativa de un gobierno itinerante en permanente campaña. Y la ilustración, el liberalismo gaditano y las aportaciones procedentes de la aún novedosa ciencia económica deberían ayudar a dar coherencia a los borradores de reforma. ${ }^{3}$

Sin embargo, no tardaron en mostrarse los límites de la compleja recomposición del Estado, y los impulsos del cambio comenzaron pronto a desdibujarse. La guerra no finalizó con la Independencia y los encontronazos fronterizos y los conflictos intestinos se consolidaron, de manera que acabaron formando parte del paisaje natural del Perú. Y mientras esto ocurría, las fuerzas centrífugas convirtieron la vida económica y política en realidades líquidas, que algunos denominaron «anarquía y caos», aunque lo apropiado sería hablar de «atomización». Entonces en el Perú convivió por largo tiempo una explosiva mezcla de sociedad altamente militarizada junto con un profundo arraigo antifiscal. Y el caudillaje emergió únicamente a modo de parche, como una solución provisional en cuya naturaleza residían las mismas esencias contra las que aparentemente combatía, instituciones desdibujadas en un marcado personalismo y mimetización de Ejército y Estado. Liquidez por liquidez. En el período de 1821 a

3. Gootenberg (1998); Flores Guzmán (2010); Haro (2011); Peralta y Haro (2019). 
1827 ni la guerra logró despejar los «viejos» hábitos, ni el proyecto político de Simón Bolívar consiguió responder a las aspiraciones del momento. Todos, que intuyeron que sin Hacienda no habría Estado, fracasaron parcialmente en un plan de largo aliento que permitiese sortear el obstáculo que ya se atisbaba en el horizonte, una Hacienda deslavazada dentro de un Estado «encogido».

\section{La guerra de la Independencia y la Hacienda peruana: desarme fiscal, secuestros y empréstito de Londres (1821-1824)}

El 3 de agosto de 1821 San Martín se erigió con el título de protector del Perú y su gobierno, que no contó con el apoyo entusiasta de una parte importante de los grupos más influyentes, ${ }^{4}$ inició su régimen sometido a la tensión de gobernar un país aún por consolidar con unas élites recelosas, unas clases populares expectantes y una guerra inacabada.

El ideario de San Martín, que significaba una oportunidad para llevar a cabo el tránsito hacia un Estado y una economía de nueva base más acorde con los tiempos de un mundo moderno, dispuso de importantes frenos que cercenaron el proyecto reformista (Fisher, 2000: 257). Y en este proceso la Hacienda no fue una excepción. El ímpetu liberal quedó embalsado con la promulgación del Estatuto Provisorio, la «libertad de vientres» y la abolición del tributo de los indios. Y con la proclamación de la independencia el 28 de julio de 1821 en la plaza de Armas de Lima, se cerraba un precario acuerdo entre buena parte de la élite limeña, la alta burocracia y las nuevas autoridades, articulando consensos que conjugaban el triple objetivo de evitar posibles embates revolucionarios, hacer frente a la amenaza militar y conservar las posiciones privilegiadas. El proceso, que implicaba un serio repliegue hacia el pasado, no estuvo exento de sorpresas, ya que el programa de gobierno incluyó un hecho inesperado: la eliminación de la élite comercial española.

Desde la perspectiva hacendística, el «pacto patriótico», que venía a sustituir al caduco «pacto colonial», se concretaba en un desmantelamiento que abría una peligrosa puerta hacia el «empobrecimiento del Estado" (Salinas, 2011: 304). Hacienda y política fueron de la mano. Una idea fuerza con la que ganar a la opinión pública, atractiva tanto para las clases populares como para hacendados y grandes comerciantes, consistió en una oferta concretada en una reducción sustancial de la presión fiscal. Asimismo, se avanzó en el proceso de privatización, al tiempo que se depositaban ciegamente las esperanzas de un importante estímulo en la recaudación vía consumos y aduanas. Hipólito Unanue, miembro del gobierno sanmartiniano como responsable del ramo de la Hacienda, aspiró a reordenar el aparato burocrático colonial, aunque sin un

4. Leguía y Martínez (1972: 425); «Número 4». La Abeja Republicana, tomo III, 1971 [1823], págs. 59-74. 
plan preciso, ${ }^{5}$ como lo prueba su premio de 2.000 pesos a aquel que presentase el mejor plan de arreglo aplicable al Perú. Con todo, pretendió adelgazar la estructura burocrática heredada y sintonizar con los grupos económicos influyentes.

Tras conocer con precisión el estado exacto en el que se encontraban los fondos disponibles en las dependencias oficiales, los ánimos se atemperaron. ${ }^{6}$ Tampoco ayudó el escaso recorrido que tuvieron las medidas encaminadas a reorganizar el aparato burocrático y reducir su masa salarial, que reportó un discreto ajuste de 43.000 pesos. ${ }^{7}$ Y la situación pronto se saldó con un arriesgado descuadre, cuando se hizo efectiva la puesta en marcha de la política de suave fiscalidad con respecto a los grupos dominantes. La Iglesia fue la primera institución en beneficiarse de la retirada impositiva. ${ }^{8} Y$ de forma paralela se trabajó con respecto al sector comercial con la aprobación del Reglamento Provisional de Comercio. ${ }^{9}$ Sin embargo, la reducción en un tercio de las tarifas arancelarias, que provocó que el mercado interno se saturara a los pocos meses del levantamiento del bloqueo sobre el puerto del Callao, desvaneció las optimistas previsiones sobre la potencial recaudación (Quiroz, 1993: 134).

Ante esta delicada situación, Unanue apostó por una iniciativa arriesgada y novedosa, ya pergeñada en los meses de febrero y marzo de 1821 por parte del gobierno del virrey La Serna: la emisión de papel moneda y la creación del Banco Auxiliar (Haro, 2017). La medida suponía un estratégico complemento a la política de fiscalidad suave que pudo significar la entrada de más de medio millón de pesos a las apuradas arcas del Estado. ${ }^{10}$ La comisión que ideó y acabó dando forma al proyecto del banco emisor estuvo formada íntegramente por miembros del Tribunal del Consulado. ${ }^{11}$

5. «Departamento de Hacienda». Gaceta del Gobierno de Lima Independiente (Lima), 1950 [1821-1822], tomo I, 22 de agosto de 1822, núm. 13, págs. 57-58.

6. Según informe del contador Joaquín Bonet, los créditos pasivos a finales de 1821 ascendían a un total de 18.161.636 pesos, y si se rebajaban los correspondientes a ramos remisibles a España restaba una cantidad reconocida de 6.449 .665 pesos. «Examen de la deuda pública». Gaceta del Gobierno de Lima Independiente, Lima, 1950 [1821-1822], tomos I, 1 de diciembre de 1821, núm. 42, págs. 214-216. Asimismo, detecta numerosas duplicidades administrativas y cuentas descabaladas en varias oficinas oficiales (Tribunal de Cuentas, Cajas Matrices, Casa de Moneda, Renta de Tabacos, Correos, Aduanas y Temporalidades). «Informe», Archivo General de la Nación (en adelante, AGN), Fondo Republicano, Ministerio de Hacienda, Caja 1, O.L. 8.

7. Gaceta del Gobierno de Lima Independiente, Lima, 1950 [1821-1822], tomo I, 1 de septiembre de 1821, núm. 16, pág. 72.

8. «Decreto». Gaceta del Gobierno de Lima Independiente, Lima, 1950 [1821-1822], tomos I, 26 de diciembre de 1821, núm. 49, págs. 195-196.

9. «Reglamento Provisional de Comercio». Gaceta del Gobierno de Lima Independiente, Lima, 1950 [1821-1822], tomo I, 6 de octubre de 1821, núm. 26, págs. 111-114 [115-118].

10. "Decreto del Protector del Perú, Ministerio de Hacienda». Gaceta del Gobierno de Lima Independiente, Lima, 1950 [1821-1822], tomo II, 9 de enero de 1822, núm. 3, págs. 275-278.

11. «Idea de un Banco Auxiliar», en Colección Documental de la Independencia del Perú (en adelante, CDIP). Obra de gobierno y epistolario de San Martín, tomo XIII, vol. 1, 1974, págs. 248-265. 
Aun así, el proyecto pronto sufrió los primeros descuadres. El secuestro y expoliación de bienes a españoles ausentes y americanos que hubiesen seguido al ejército realista ${ }^{12}$ derivó en una confiscación general. La eliminación económica del grupo de peninsulares y criollos denominados jurídicamente como españoles, que en la ciudad de Lima alcanzaba las diez mil personas, tuvo como objetivo el refuerzo de lealtades políticas, la vivificación de nuevos grupos económicos de influencia en el país y la reducción del enorme déficit que la política de baja presión fiscal comenzaba a manifestar en los balances oficiales. Aun así, la eliminación como grupo social susceptible de conformar una oposición interna favorable a la vuelta del virrey a Lima tuvo un alto coste. El Juzgado de Secuestros, constituido el 16 de octubre de 1821 y pilotado por Francisco Valdivieso en calidad de juez, procedió con determinación y rapidez, tal como lo mandataba el artículo cuarto del reglamento: «Los juicios de secuestros han de ser breves y sumarios, omitidas las dilaciones perjudiciales a las partes, y a la causa pública; y sin observar otros trámites que los precisos para esclarecer la verdad, y proceder en justicia»..$^{13}$

La política de secuestros, que se acentuó con el decreto de 1 de febrero de 1822, requisó haciendas, propiedades urbanas y activos comerciales, que rápidamente fueron adjudicados a líderes militares patrióticos y otros miembros de la aristocracia local. ${ }^{14}$ Además, los abusos generalizados y la corrupción rampante acabaron por limitar extraordinariamente las posibilidades de ensanchar por esta vía las bases fiscales del sistema. ${ }^{15} \mathrm{Y}$ el proceso de expoliación terminó desembocando en un abierto enfrentamiento entre el Gobierno y el Tribunal del Consulado con efectos directos en la dirección y gestión del Banco Auxiliar. El Tribunal del Consulado pasó a denominarse Cámara de Comercio y el conde de Villar de Fuente, prior del Tribunal y director del banco, fue obligado a abandonar ambos cargos en marzo de 1822 debido al procesamiento abierto ante la Alta Cámara. ${ }^{16}$ La entidad terminó por hundirse en el verano de $1822 .{ }^{17}$ Pero la pérdida del Banco Auxiliar y el cierre de la emisión de papel moneda fue un asunto menor. La forma con la que se azuzó el sentimiento antiespañol galvanizó a las clases populares contra el conjunto de españoles residentes en Lima, y a la destrucción y confiscación de «bodegas, chinganas, tiendas y panaderías» se sumó una violenta y amplia expropiación por parte del gobierno, que redujo a una triste sombra a la vieja «aristocracia mercantil» (Flores Galindo, 1991: 170-175) y dejó a la capital mermada de grupos influyentes con los que articular la acción

12. "Secuestros", en CDIP. Obra de gobierno y epistolario de San Martín, tomo XIII, vol. 1, pág. 84

13. «Juzgado». Gaceta del Gobierno de Lima Independiente, Lima, 1950 [1821-1822], tomo I, 1 de septiembre de 1821, núm. 16, pág. 72.

14. "Juzgado Privativo de Secuestros", en AGN, Fondo Republicano, Colección Diéguez 9.29.88, Secuestros 466.79 (4) y 466.84 (2).

15. «Fincas del Estado». La Abeja Republicana, Lima, tomo III, 1971 [1823], págs. 105-119.

16. «Cese», en AGN, Fondo Republicano, Ministerio de Hacienda, caja 7, O.L. 42-22; y «Nombramiento» en AGN, Fondo Republicano, Ministerio de Hacienda, caja 8, O.L. 10.

17. «Extinción». Gaceta del Gobierno de Lima Independiente, Lima, 1950 [1821-1822], tomo III, 13 de agosto de 1822, núm. extraordinario, págs. 601-602. Aunque la agonía se prolongó hasta finales de 1824. 
política. Todo ello en un ambiente acuoso que fomentaba la percepción antifiscal de los grupos influyentes hacia el Estado y de las clases populares hacia estos grupos, como lo demuestra, por ejemplo, el hundimiento en paralelo y generalizado de los diezmos eclesiásticos. ${ }^{18}$

El balance hacendístico tras el primer año de guerra resultaba temerario: los gastos aumentaban sin descanso empujados por la guerra, mientras que los ingresos se desplomaban debido a la brusca retirada del sistema fiscal heredado del plan de 1815, el abrupto corte de transferencias por parte de los departamentos «liberados» ${ }^{19}$ y la interrupción de la actividad minera, con la consecuente suspensión de los circuitos comerciales. Sin embargo, más allá de la tendencia a agrandar un déficit ya de por sí abultado a inicios de 1821, el mayor desequilibrio se desveló con la emergencia de una estructura fiscal inestable. Los ingresos ordinarios, reducidos a las aportaciones regulares pero decrecientes del Consulado y la Aduana, una menguante Casa de la Moneda y otras rentas menores, quedaban ampliamente superados por las entradas extraordinarias, ya fuesen donativos, empréstitos, papel moneda, secuestros o pasaportes; pero, si bien puntualmente podían suponer cargos importantes, su naturaleza ajena a la dinámica económica convertía estos ingresos extraordinarios en entradas esporádicas, sin continuidad y, en el caso de los préstamos, con gravosas contraprestaciones (cuadros 1 y 2 ).

Llegados a este punto, no resulta difícil imaginar la delicada tesitura en la que quedó el Protectorado. La falta de fondos comprometía al conjunto del sistema, que se hallaba a expensas de los inciertos resultados que la comisión García del Río-Paroissien pudiera cosechar en la negociación del empréstito internacional en Londres (Contreras, 2001: 220). Y perdida la Hacienda, el Gobierno estaba condenado. La expulsión del ministro de Guerra, Bernardo de Monteagudo, ${ }^{20}$ fue el prólogo de un fracaso anunciado. San Martín, con el fiasco cosechado en su entrevista con Bolívar en Guayaquil y la caótica situación larvada en Lima, pronto tuvo que abandonar. El final del régimen también significó la sonora salida de Unanue del gobierno en medio de un tenso debate público que tuvo largo recorrido. ${ }^{21}$ En la Memoria presentada por el exministro al Congreso del Perú en la sesión del 23 de septiembre de 1822, adelantó datos preocupantes, que básicamente coinciden con el análisis cuantitativo de los balances de la Tesorería General. Unanue fue consciente de una peligrosa tendencia cuando señaló que «se percibe con claridad que las rentas del Estado no podrán seguir soportando los gastos, si no se ensanchan sus límites». ${ }^{22}$ Imploró en sus últimas líneas lo que estuvo ausente en su acción ministerial, «vivificar» los impuestos.

18. "Asunto eclesiástico», en CDIP, tomo XIV, Obra gubernativa y epistolario de Bolívar, Legislación de 1826, vol. 2, Lima, 1975, pág. 322.

19. Solo el departamento de La Libertad transfirió fondos a todas luces insuficientes. La respuesta de Monteagudo fue reveladora del caos descentralizador (CDIP, tomo XIII, Obra de gobierno y epistolario de San Martín, vol. 1, pág. 104).

20. «Exposición» en Biblioteca Nacional del Perú (en adelante, BNP), Fondo Antiguo 1000009326.

21. «Números 7 y 14». La Abeja Republicana, Lima, tomo II, 1971 [1823], págs. 118-120 y 239-244.

22. «Memoria del ministro de Hacienda», en BNP, Fondo Antiguo 1000004047. 
En palabras del ministro, el déficit resultante en el primer año desde la declaración de independencia arrojaba un monto aproximado de 1.444 .000 pesos, tras apuntar gastos superiores a los 2.700 .000 pesos e ingresos de poco más de 1.300.000. En efecto, los datos contrastados confirman estas estimaciones. Pero con matices. El grueso de los ingresos ordinarios, incluidas las rentas de Tabaco, ascendieron a 1.187.769 y los gastos totales alcanzaron los 2.867.306 pesos. Y lo que ocultó el ministro fue la referencia de que los ingresos totales del período superaron los 2.800 .000 pesos, dejando a oscuras la gestión relativa a los procesos de secuestros y la negociación de los empréstitos. Su tiempo político, de momento, había caducado. Pasado más de un año de la declaración de independencia, en términos hacendísticos se estaba en tierra de nadie. Y la administración estatal asistió a una rápida descomposición cuando el capital extranjero tardó en proveer de los primeros fondos con regularidad.

Cuadro 1. Ingresos fiscales (en pesos) (1821-1822).

\begin{tabular}{|c|c|c|c|c|c|c|c|c|}
\hline \multirow{1}{*}{$\mathbf{1 8 2 1 - 1 8 2 2}$} & Ingresos & \multicolumn{5}{|c|}{ Ingresos ordinarios } & \multicolumn{2}{|c|}{ Ingresos extraordinarios } \\
\hline agosto & & Consulado & Aduana & Barras & Acuñación & Donativo & Billetes & Otros \\
\hline septiembre & 130.659 & 36.319 & 14.394 & & & 19.593 & & \\
\hline octubre & 164.184 & 32.336 & 50.401 & & & & & \\
\hline noviembre & 307.978 & 60.344 & 59.967 & 21.706 & & 99.142 & & \\
\hline diciembre & 159.678 & & 36.000 & 23.818 & & & & \\
\hline enero & 192.386 & & 116.727 & 4.897 & 12.000 & & & \\
\hline febrero & 241.341 & & 31.779 & 10.957 & & & 80.000 & \\
\hline marzo & 226.223 & & 45.317 & 6.417 & & & 20.000 & \\
\hline abril & 459.652 & 18.161 & 100.474 & & & 118.680 & & \\
\hline mayo & 144.456 & & 39.750 & 7.674 & 8.693 & & 50.000 & \\
\hline junio & 308.830 & 118.000 & 21.146 & 4.955 & 11.190 & & 50.000 & \\
\hline julio & 258.571 & 15.041 & 49.943 & 6.309 & & & 50.000 & \\
\hline agosto & 225.665 & & 77.408 & & 41.758 & & & \\
\hline TOTAL & 2.819 .623 & 300.201 & 643.306 & 86.733 & 73.641 & 249.980 & 250.000 & \\
\hline
\end{tabular}

Nota: Los ingresos extraordinarios contemplados en la columna «Otros» incluyen: préstamo de Estanislao Lynch, Secuestros, Cabildo y Caja de Trujillo. En «Ingresos ordinarios», la Renta de Tabaco ascendió en el período del cuadro a 83.888 pesos.

Fuente: Elaboración propia a partir de los datos contenidos en "Tesorería General del Estado» en CDIP, Obra de gobierno y epistolario de San Martín, tomo XIII, vol. 1, 1974, págs. 119-232. Y complementados con los Libros Mayores de la Caja Matriz del Estado de Lima, 1821 y 1822 en AGN, Fondo Republicano, Hacienda H-4-1580 y H-4-1562. 
Cuadro 2. Gastos fiscales (en pesos) (1821-1822)

\begin{tabular}{|c|r|r|r|r|r|r|r|}
\hline 1821-1822 & Gastos & Ejército & Comisarías & Guerra & Oficiales & Estado & Pensiones \\
\hline agosto & 27.013 & & & & & & \\
\hline septiembre & 147.618 & 102.031 & & & & & \\
\hline octubre & 160.784 & & & & & & \\
\hline noviembre & 221.133 & & & & & & \\
\hline diciembre & 197.204 & & & & & & \\
\hline enero & 214.256 & & & & & & \\
\hline febrero & 252.748 & & & & & & \\
\hline marzo & 238.067 & 103.380 & 60.780 & 13.567 & 4.017 & 19.001 & 37.319 \\
\hline abril & 359.109 & 122.296 & 111.465 & 59.335 & 7.126 & 20.011 & 38.873 \\
\hline mayo & 249.633 & 136.375 & 38.474 & 26.122 & 9.205 & 20.099 & 19.356 \\
\hline junio & 308.772 & 118.443 & 60.779 & 61.534 & 10.539 & 19.324 & 38.159 \\
\hline julio & 269.777 & 129.807 & 60.998 & 36.934 & 5.417 & 20.642 & 15.978 \\
\hline agosto & 221.192 & 117.547 & 20.376 & 38.259 & 3.839 & 21.799 & 19.370 \\
\hline TOTAL & 2.867 .306 & 727.848 & 352.872 & 235.751 & 40.143 & 120.876 & 169.055 \\
\hline
\end{tabular}

Nota: En «Estado» se incluyen los gastos de Hacienda, Justicia y el cuerpo político.

Fuente: Elaboración propia a partir de los datos contenidos en «Tesorería General del Estado» en CDIP, Obra de gobierno y epistolario de San Martín, tomo XIII, vol. 1, 1974, págs. 119-232. Y complementados con los Libros Mayores de la Caja Matriz del Estado de Lima, 1821 y 1822 en AGN, Fondo Republicano, Hacienda H-4-1580 y H-4-1562.

El 20 de septiembre de 1822 se instaló el Primer Congreso Peruano, que nombró una Junta de Gobierno presidida por José de La Mar. La acelerada dinámica política en que quedó sumido el Perú independiente a finales de 1822 y 1823 paralizó cualquier intento de replanteamiento hacendístico de calado. Los sucesivos ministros de Hacienda, Francisco Valdivieso, Mariano Vidal y Dionisio Vizcarra, poco pudieron hacer en medio del caos. Tampoco la comisión de Hacienda creada por el Congreso, conformada por Francisco Agustín de Argote, Manuel Ferreyros, José Gregorio Paredes, Pedro Pedemonte, José de Iriarte y José Antonio de Alcázar, obtuvo mejores resultados. ${ }^{23}$ Los debates se fueron dispersando en una compleja maraña de heterogéneas iniciativas que abarcaron desde la negociación del empréstito con el comercio inglés, hasta farragosos debates en torno a la amortización del papel moneda. La prueba de que los asuntos fiscales habían perdido el hilo fue el hecho de que el departamento de Hacienda fuera habitualmente ocupado de forma interina. ${ }^{24}$ Mientras, la derrota

23. «Debates», en CDIP, tomo xv, Primer Congreso Constituyente, vol. 1, 1973, págs. 125-126. 24. Entre el 21 de septiembre de 1822 y el 2 de abril de 1823, por Francisco de Paula Valdivieso. 
de la Primera Campaña de Intermedios, en enero de 1823, agitó las turbulentas aguas de la política peruana. Las disputas políticas se avivaron y tras el motín de Balconcillo, el 27 de febrero de 1823, José de la Riva-Agüero y Sánchez Boquete fue proclamado primer presidente del Perú. Según recogió el periódico $L a$ Abeja Republicana en su número correspondiente al 14 de diciembre de 1822, la situación económica y el estado de las rentas eran deplorables. ${ }^{25} \mathrm{Y}$ con un aparato fiscal desmazalado, la política de rebajas fiscales, refrendada con la ley de supresión del derecho de décima y la ley de supresión del cobro de arrendamientos sobre predios, colaboró al arraigo antifiscal (Dancuart, 1902, I: 250 251). Asimismo, el alivio que inicialmente supuso la inyección de los primeros fondos a cargo del empréstito de Londres de 1822 pronto se frustró. El empréstito que había permitido nuevos bríos financieros se agotó como fuego fatuo en medio de una opaca y discutida gestión. Las actas secretas del Congreso Constituyente registraron numerosas irregularidades en la gestación del empréstito por parte de los comisionados ${ }^{26}$ y Unanue aludió a posibles malversaciones y negligencias en la tramitación del préstamo (Dancuart, 1902, I: 260).

Con la severa derrota en la Segunda Campaña de Intermedios, la naciente república quedó sin márgenes financieros. Y en el plano político, el Estado se hundía en una espiral de división política y debilidad militar. El 23 de junio se nombró ministro de Hacienda a Dionisio Vizcarra. Y en el período en el que José Bernardo Tagle, por mandato de Antonio José de Sucre, se hizó cargo temporalmente del alto mando del país hasta su nombramiento como presidente de la República por el Congreso del Perú, Vizcarra se convirtió en su mano derecha. Sin embargo, la Hacienda siguió perdida ${ }^{27}$ y la coyuntura política derivó en un laberinto sin puertas.

Entonces, Simón Bolívar entró en la capital el 1 de septiembre y el Congreso otorgó al Libertador poderes dictatoriales. El escenario político comenzó a despejarse. Riva-Agüero, destituido por el Congreso e instalado con su gobierno en Trujillo, tuvo que tomar en noviembre rumbo al exilio y Torre Tagle inició un camino sin retorno hacia la irrelevancia. El 24 de septiembre de 1823 Unanue volvía al gobierno y en octubre, tras la recepción de parte de Francisco Taramona de 1.029.856 pesos en 80 billetes contra el empréstito de Londres, retomaba la Hacienda Nacional un pulso perdido. Estos fondos estratégicos se sumaron a una cascada de heterogéneas medidas que, a pesar de no formar parte de un plan fiscal coherente, no dejaba de ser algo distinto a lo acostumbrado hasta el momento. Una reorientación, al menos. Primero, porque impuso una contribución forzosa directa sobre todas las clases del Estado por un monto total de 400.000 pesos en cuatro mensualidades. Luego, porque aprobó un empréstito sobre el comercio de Lima por 200.000 pesos, aunque al alto coste de ceder a los prestamistas elevadas cuotas sobre los derechos de aranceles, privatizando de iure

25. «Número 1». La Abeja Republicana, Lima, tomo II, 1971 [1822], págs. 1-18.

26. «Actas», en CDIP, tomo xv, Primer Congreso Constituyente, vol. 2, 1974, págs. 221-223; 252-252, 318-319 y 322.

27. «Actas secretas del Congreso Constituyente», en CDIP, tomo xv, Primer Congreso Constituyente, 1974, vol. 2, págs. 273 y 312. 
la gestión de la Aduana ${ }^{28}$ Y más tarde, porque creó la «única contribución», mediante el Decreto de 12 marzo de 1824, e impulsó una profunda revisión al alza de los derechos de aduanas (Dancuart, 1902, I: 222, 252-255 y 257-258).

Sin embargo, para la evaluación de la última etapa de la guerra contamos con un obstáculo insalvable: la falta de estadísticas oficiales. Los datos cuantitativos de los que disponemos para el período comprendido entre el segundo semestre de 1822 y enero de 1825 son erráticos y heterogéneos, por lo que impiden una rigurosa reconstrucción de series hacendísticas. ${ }^{29}$ Entre septiembre y diciembre de 1823 las únicas entradas reseñables en la Tesorería General de Lima son las correspondientes al rubro de aduanas, con un máximo mensual de 118.000 pesos y un mínimo de 30.000 , salvo la extraordinaria entrada antes citada de 1.029.856 a cargo del empréstito. Ese mismo mes fueron desviados a la secretaría del Libertador 400.000 pesos antes de su salida de la capital en dirección al norte, mientras que el resto se dejó para sostener el ejército en Lima. El año de 1824 fue aún peor, con una República sin Lima, en la que los registros contables se hicieron aún más imprecisos, y el ejercicio fiscal finalizó con un apagón estadístico de facto que dejaba atrás los días de las epopeyas, y con un Estado prácticamente desaparecido y solo sostenido por un precario apunte contable en la partida de existencias de la Tesorería General de 670.000 pesos a cargo del citado empréstito. Fueron tiempos negros en los que la turbia contabilidad fue de la mano de la corrupción (Quiroz, 2014: 103-110).

\section{Entre la reforma y la tradición: los límites del modelo fiscal republicano (1825-1827)}

Concluida la guerra a finales de 1824, quedaba por delante un largo camino para el replanteamiento de la Hacienda de la República del Perú. Unanue, que había vuelto a asumir las funciones de ministro del ramo el 28 de octubre de 1824, relató el enorme reto que tenían por delante:

En el tiempo en que la patria ha luchado, con varia suerte, para conseguir su independencia, he sido llamado tres veces a desempeñar el Ministerio de Hacienda. En las dos primeras existían algunas ruinas para reparar el edificio; más ahora han desaparecido hasta los escombros (Dancuart, 1902, I: 259).

Y defendió, entre los puntos centrales para la reorganización de la Hacienda Pública, el «arreglo para una contribución en proporción a los haberes de los individuos" (Dancuart, 1902, I: 262). Dejando de lado la controversia en torno a si la contribución citada se trataba de un impuesto sobre la renta o más bien sobre el patrimonio, su simple propuesta abría las puertas a una pieza im-

28. «Proyecto», en BNP, Fondo Antiguo, 1000045531.

29. Libros Mayores de la Caja Matriz del Estado de Lima, 1823 y 1824, en AGN, Fondo Republicano, Hacienda H-4-1570 y H-4-1579. 
positiva central sobre la que ensanchar la base fiscal del sistema, un tributo directo a través del cual los contribuyentes aportarían un tanto proporcionado de sus «fortunas, caudales, haberes o facultades» al Erario. El aprendizaje parecía que daba sus frutos y a la tarea de hacer viable la nación con un sistema hacendístico solvente se sumaron José de Larrea y Loredo y José María de Pando.

En 1825, con la guerra concluida, salvo el endiablado sitio del Callao, los ánimos invitaban al optimismo. Y en enero se volvió a contar con una inyección in extremis y estratégica de 1.111.256 pesos a cargo del segundo empréstito de Londres. En palabras de Bolívar, había llegado el momento de imprimir un cambio al proceso de institucionalización de la nación, y según señaló el 10 de febrero al Congreso Constituyente: «mi administración no puede llamarse propiamente, sino una campaña», ${ }^{30}$ y subrayó la inexistencia de rentas nacionales. Entonces el gobierno se puso manos a la obra disponiendo de un amplio margen de maniobra cuando el Libertador, con motivo de su viaje a los departamentos del sur, delegó el mando político y militar en el Consejo de Gobierno. ${ }^{31}$ Tras la obligada remodelación del 16 de marzo, motivada por la convalecencia de José Sánchez Carrión que elevó a Unanue a la cartera de Gobierno y Relaciones Exteriores y dio entrada a José María Pando en Hacienda, las medidas se sucedieron con relativa celeridad. De forma inmediata, los esfuerzos se centraron en la reactivación de la «única contribución», cuyos resultados habían quedado lejos de sus iniciales metas. Se volvía así a la tributación directa y personal en proporción a la propiedad y de carácter mensual. Predios rústicos, urbanos y un impuesto sobre todas las clases de industria conformaron los rubros que deberían ser recaudados, y se encomendó a los jueces de cuartel en las ciudades y los intendentes y gobernadores en los demás pueblos el levantamiento de los censos y la asignación de las cuotas personales. Además, se reanudó la actividad de la Casa de la Moneda y una amplia reestructuración en la administración estatal removió cargos desde la Contaduría Mayor hasta las principales prefecturas, pasando por la Junta de Liquidación. Asimismo, mediante el Decreto de 24 de abril, José María de Pando aprobó el reglamento orgánico de la Caja de Amortización de la Deuda Pública, serio proyecto encaminado a fijar los medios, fondos y procedimientos a través de los cuales extinguir la deuda interior y exterior. Con ligeras resonancias en las cajas homónimas de la península, la iniciativa se erigió a modo de pieza clave con la que comenzar a poner orden en las deshilachadas finanzas públicas. ${ }^{32}$ Fueron meses de avances e interrupciones. Si bien, por una parte, la construcción de la estructura hacen-

30. «Mensaje al soberano Congreso» en CDIP, tomo xIv, Obra gubernativa y epistolario de Bolívar, vol. 1, Lima, 1975, pág. 318.

31. Consejo de Gobierno compuesto por: José de La Mar, presidente; José Sánchez Carrión, ministro de Gobierno y Relaciones Exteriores; e Hipólito Unanue, ministro de Hacienda. La persona de enlace entre el Consejo y el Libertador lo desempeñó con celo el general José Gabriel Pérez en calidad de secretario personal de Bolívar.

32. «Reglamento orgánico de la Caja de Amortización de la Deuda Pública», en CDIP, tomo XIV, Obra gubernativa y epistolario de Bolívar, vol. 1, Lima, 1975, págs. 469-476. 
dística se vio galvanizada cuando llegaron los fondos procedentes del exterior, por otra, el desbarajuste fiscal procedente de los departamentos del país y el continuo drenaje de fondos por parte de un Ejército embarcado en una campaña interminable evidenciaron la persistencia de obstáculos aparentemente insalvables.

Así, el Gobierno, viendo los pobres resultados obtenidos a pesar del amplio abanico de medidas implementadas, puso el acento en las tarifas arancelarias y aumentó los derechos de importación sobre los comerciantes extranjeros. Asimismo, en el Ministerio de Hacienda se acometió una reorganización interna en la que se nombró a José Morales y Ugalde visitador general de oficinas y rentas y se promocionó a Manuel Lino Ruiz Pancorvo a contador de la Contaduría General de Cuentas. Y a finales de año se incluyó un vasto programa de privatización de bienes nacionales de largo alcance que incluían minas, tierras baldías y propiedades adscritas a la Dirección General de Censos. ${ }^{33}$ Sin embargo, los balances oficiales cuentan otra historia (cuadros 3 y 4).

Cuadro 3. Ingresos fiscales correspondientes a 1825 (en pesos).

\begin{tabular}{|c|r|r|l|l|l|r|}
\hline & \multicolumn{1}{|c|}{ Ingresos } & \multicolumn{3}{|c|}{ Ingresos ordinarios } & \multicolumn{2}{c|}{ Ingresos extraordinarios } \\
\hline & & Aduana & Departamentos & Acuñación & $\begin{array}{c}\text { Empréstito } \\
\text { Londres }\end{array}$ & $\begin{array}{c}\text { Otros } \\
\text { empréstitos }\end{array}$ \\
\hline Enero & 1.151 .883 & 29.254 & & & 1.111 .256 & \\
\hline Febrero & 27.150 & 16.935 & & & & \\
\hline Marzo & 70.104 & 66.863 & & & & \\
\hline Abril & 31.048 & 26.366 & & & & \\
\hline Mayo & 155.387 & 144.903 & & & & \\
\hline Junio & 104.453 & 69.744 & 19.993 & & & \\
\hline Julio & 65.963 & 34.607 & 23.725 & & & \\
\hline Agosto & 247.240 & 114.836 & 44.155 & & & 25.000 \\
\hline Septiembre & 93.874 & 62.441 & 10.028 & & & 35.000 \\
\hline Octubre & 113.550 & 96.276 & 41.459 & & & 83.000 \\
\hline Noviembre & 245.836 & 72.612 & 52.188 & 50.000 & & 17.500 \\
\hline Diciembre & 173.950 & 88.894 & & & & 49.500 \\
\hline Total & 2.480 .438 & 823.731 & 191.548 & 50.000 & & 210.000 \\
\hline
\end{tabular}

Fuente: Elaboración propia a partir de los datos recogidos en: «Tesorería General», en CDIP, tomo XIV, Obra gubernativa y epistolario de Bolívar, vol. 1, 1975, págs. 302-307, 363-366, 487-491, 548-553, 598$603,636-643,677-683$ y $745-751$.

33. «Al Sr. Ministro de Estado», ibídem, págs. 787-788. 
Cuadro 4. Gastos fiscales correspondientes a 1825 (en pesos).

\begin{tabular}{|c|r|c|c|c|c|}
\hline $\mathbf{1 8 2 5}$ & Gastos & Ejército & Burocracia & $\begin{array}{c}\text { Guillermo } \\
\text { Cochrane }\end{array}$ & $\begin{array}{c}\text { Otros } \\
\text { acreedores }\end{array}$ \\
\hline Enero & 141.654 & & & 1.011 .256 & 100.000 \\
\hline Febrero & 27.139 & & & & \\
\hline Marzo & & & & & \\
\hline Abril & 43.139 & & & & \\
\hline Mayo & 115.117 & & & & \\
\hline Junio & 74.103 & & & & \\
\hline Julio & 55.559 & 39.461 & 16.127 & & \\
\hline Agosto & 203.182 & 170.621 & 32.561 & & \\
\hline Septiembre & 133.833 & 114.030 & 19.802 & & \\
\hline Octubre & 259.601 & 189.737 & 69.863 & & \\
\hline Noviembre & 253.414 & 235.606 & 17.808 & & \\
\hline Diciembre & 181.305 & 145.611 & 32.787 & & \\
\hline Total & 1.488 .046 & & & 1.011 .256 & 100.000 \\
\hline
\end{tabular}

Nota: En el presente cuadro no figuran las cuentas relativas a la Comisaría General del Ejército Unido, una institución militar dentro del Estado separada y singular. Sus ingresos proceden, en un porcentaje superior al $80 \%$, de préstamos concedidos por Guillermo Cochrane y complementados mediante entradas de metales preciosos y transferencias de Aduanas. La disponibilidad de datos se circunscribe al período comprendido entre enero y agosto y suma un total de 680.566 pesos.

Fuente: Elaboración propia a partir de los datos recogidos en: CDIP, tomo XIV, Obra gubernativa y epistolario de Bolívar, vol. 1, Lima, 1975, págs. 302-307, 363-366, 487-491, 548-553, 598-603, 636-643, 677-683 y 745-751.

El modelo fiscal por el que se acabó decantando no se separó en gran medida de su homónimo sanmartiniano. Apenas se movió nada. Bolívar fue más liberal (Paniagua, 2007) que revolucionario y la actividad legislativa, a veces febril, adoleció de cierto alejamiento de la realidad y debilidad inherente, cuando el incumplimiento de la norma se hizo habitual y la cuestión fiscal fue progresivamente orillada. Las reformas hacendísticas fueron embarrancando entre la desidia y el desinterés. ${ }^{34}$ De forma natural, y en ausencia de un aparato estadístico preciso con el que levantar censos y padrones, el sistema fiscal resultante acabó apoyándose casi en exclusiva sobre los impuestos indirectos, las aduanas y los consumos, en estrecha sintonía con procesos sociales y económicos que se daban en paralelo. En una situación propicia para la ruralización (Méndez, 2014), con un pulso comercial decreciente y cegada la actividad minera, limitando extraordinariamente las oportunidades de inversión capitalistas, los capitales y las rentas de forma natural se orientaron a la adquisición de tierras. La revolución liberal, que abrió la posibilidad de reestructurar el mundo agrario en torno a la propiedad privada y los procesos de desamorti-

34. «Intendentes sin sueldo», ibídem, pág. 415. 
zación (Armas, 2010: 49-63), ofreció la oportunidad de la concentración (Lynch, 2006: 209-213 y 380-385).

La patente pérdida de poder de las élites coloniales sirvió a su vez para crear las condiciones precisas que favoreciesen la aparición de un Estado nuevo capaz de representar institucionalmente los intereses de una reinventada clase dirigente. Una élite renovada, en la que grandes hacendados, unidos a significados representantes del comercio internacional y una retahíla de miembros reseñables de la alta burocracia civil y militar, aspiraban a desempeñar el papel de gozne entre las autoridades y las clases populares. Tras el desmoronamiento del régimen virreinal, el poder se había diluido entre las nuevas instituciones nacionales, creadas desde la base del pueblo con la finalidad de derrotar al «usurpador», y las instituciones tradicionales, rotas, renombradas, pero en pie. Correspondería a la dictadura de Bolívar, en primera tentativa, y al liberalismo peruano, en segunda, la misión histórica de recomponer la situación, aunque las cosas ya nunca volverían a ser lo mismo. Con Bolívar se realizaron los primeros tanteos encaminados a recuperar los niveles de ingresos que el Estado virreinal habían alcanzado en un pasado no tan lejano. Pero los resultados obtenidos fueron decepcionantes. Con una estructura fiscal que perseveró en la imposición indirecta y la privatización de bienes nacionales, el Estado, que debía convertirse en garante de los intereses de la clase dominante y elevarse como bastión inexpugnable frente a la creciente y alarmante atmósfera militarizada y el ambiente antifiscal, quedó expuesto a un futuro de insolvencia. Y paradójicamente, en su fracaso parcial anidaba la rehabilitación de la élite. Es decir, asentada esta sobre una base nueva, el fortalecimiento de la propiedad territorial a través de la compra de terrenos e inmuebles privados, la exención en el pago de impuestos se convirtió en un factor central para su recuperación. ${ }^{35}$ La propiedad de la tierra se convertía, así, en el cemento del renovado edificio, y la liberalización del individuo como sujeto fiscal, en el modo con el que sacudirse las argollas estamentales del pasado. La estructura productiva de la nación, mientras persistiera el parón minero, no disponía de otros resortes que las explotaciones agrarias para proveerse de los medios necesarios con que sostener un aparato del Estado bajo mínimos. El peso de la agricultura era abrumador, mientras que la clase industrial tenía una presencia simbólica y los grupos mercantiles habían encogido drásticamente debido a la grave crisis minera (Deustua, 2009) y su efecto de arrastre en el mercado laboral circunscrito al sector servicios. Sin embargo, el proceso no fue sencillo ni estuvo exento de resistencias. La clase dirigente nunca hizo cesión significativa a ninguna institución representativa, más allá de «tolerar» la dictadura de Bolívar, y sus capitales quedaban atesorados en fundos rústicos y urbanos sometidos a una blanda fiscalidad que se prolongó más allá de los años treinta (Córdova y Urrutia, 1839: 39). Asimismo, el futuro paraguas proteccionista también colaboraría en la recuperación de las rentas territoriales. Los terratenientes jamás delegaron sus po-

35. «Departamento de Hacienda», en CDIP, tomo XIV, Obra gubernativa y epistolario de Bolívar, Legislación de 1826, vol. 2, Lima, 1975, pág. 99; «Circular a Prefectos», ibídem, pág. 110. 
deres, de modo que, mientras cada uno de ellos actuaba como propietario absoluto en sus dominios, el Estado se encontraba con que a la institución que encarnaba le faltaba contenido efectivo. Y el caparazón se resquebrajaba en una lógica de debilidad mutua entre las clases dirigentes y el Estado, conduciendo al sistema a la tan cacareada anarquía.

En 1826 la coyuntura no mejoró y al anhelado proceso de transición se le fueron sumando fricciones y desajustes. El estallido del Pánico de 1825 en la Bolsa de Londres, con incesantes réplicas a lo largo de 1826, que supuso la quiebra de decenas de entidades bancarias y la peligrosa deriva del Banco de Inglaterra, sumado a la declaración en moratoria por parte del Perú que cesó el pago de la deuda externa, impidieron el acceso a los mercados financieros internacionales (Vizcarra, 2011: 11). Y una de las herramientas de estabilización fiscal, como había sido la contratación de empréstitos extranjeros, se esfumó. ${ }^{36}$ Entonces, hubo que volver a recuperar la senda del recorte del gasto estatal. Reconocido el hecho de que el nivel de ingresos del Estado no alcanzaba a cubrir sus respectivas necesidades y que era indispensable adoptar medidas con las que nivelar las entradas con las salidas, se comenzaron a aprobar disposiciones encaminadas a reducir la práctica totalidad de las partidas. A partir de abril, la reducción salarial de la lista civil y militar empezó a adoptarse de forma progresiva. $^{37}$

El 1 de junio de 1826 se procedió a un ajuste ministerial que dio como resultado un gabinete conformado por Hipólito Unanue, como ministro de Justicia y Negocios Eclesiásticos; José María de Pando, en la cartera de Relaciones Exteriores e Interior; y José de Larrea y Loredo, como máximo responsable del departamento de Hacienda. Y en poco tiempo varios proyectos vieron la luz. El 6 de junio se sacó adelante un nuevo reglamento de comercio, que incluía la abolición de las aduanas interiores; el 20 se creó el banco de rescate de plata y se autorizó la fundación de la empresa de minas de Pasco; y el 27 se sustanció un elaborado plan de amortización de la deuda interna. Esta última ola reformista bolivariana se completó con la aprobación entre el 9 y el 11 de agosto de los decretos de organización del Ministerio de Hacienda, ${ }^{38}$ el decreto de contribución de gremios, con la correspondiente tarifa general de patentes, y la tabla de contribuciones. Las medidas conformaban sobre el papel un coherente programa de reformas, imperfecto pero alejado del relativo caos en el que se habían manejado las finanzas republicanas en los años de la guerra. Sin embargo, la prueba de que la Hacienda no se estaba desenvolviendo como se esperaba fue la restauración, en el mes de julio, del tributo indígena, cuando no había transcurrido ni un año desde su abolición. Con todo, la vuelta al modelo colonial no quedó ahí, y a finales de 1826, por una parte, quedaban derogadas o minimizadas las medidas fiscales que supusiesen cargas sobre la renta y la propiedad,

36. «Empréstitos», en Archivo Histórico del Instituto Riva Agüero, Fondo Althaus, ALTH 16 y 17. AGN, Hacienda, Documentos oficiales H-1.O.L.145-324.

37. "Al Sr. Ministro de Hacienda», en CDIP, tomo XIv, Obra gubernativa y epistolario de Bolívar, Legislación de 1826, vol. 2, Lima, 1975, pág. 52.

38. AGN, Hacienda, Documentos oficiales «Reorganización», H-1.O.L.120-39. 
$\mathrm{y}$, por otra, fueron resucitados viejos rubros mercantiles tamizados bajo un moderado proteccionismo (Lynch, 2006: 215-218; Gootenberg, 1998: 44-49).

Entonces, las expectativas se emborronaron. Un modelo fiscal «híbrido» (Salinas, 2011: 303), que aparentemente incorporaba al sistema a criollos y mestizos una vez recuperado el tributo indígena, se fue decantando, pero con notorios desequilibrios que penalizaban a la población indígena frente al resto, a los arrendatarios frente a los propietarios, con impuestos directos sin mordiente y fuertemente escorado hacia la tributación indirecta. Todo ello con el esperado resultado de una insuficiencia fiscal que se arrastraría hasta las reformas hacendísticas de Ramón Castilla (cuadros 5 y 6).

Cuadro 5. Ingresos fiscales 1826-1828 (en pesos).

\begin{tabular}{|c|c|r|c|c|c|c|}
\hline Años & Ingresos & Aduana & Departamentos & Contribuciones & $\begin{array}{c}\text { Empréstito } \\
\text { Londres }\end{array}$ & $\begin{array}{c}\text { Venta } \\
\text { de minas }\end{array}$ \\
\hline 1826 & 2.930 .611 & 399.484 & 447.644 & & 106.712 & 417.560 \\
\hline 1827 & 2.552 .570 & 1.196 .755 & 594.307 & 24.314 & & \\
\hline 1828 & 2.605 .508 & 1.174 .184 & 473.152 & 185.437 & & \\
\hline 1829 & 2.849 .570 & 1.031 .582 & 483.428 & 101.930 & & \\
\hline 1830 & 1.808 .613 & 931.042 & 400.524 & 60.758 & & \\
\hline
\end{tabular}

Fuente: Elaboración propia a partir de los fondos documentales AGN, Fondo Republicano, Ministerio de Hacienda, H-4-1630, H-4-1637, H-4-1644 y H-4-1692.

Cuadro 6. Gastos fiscales correspondientes a 1825 (en pesos).

\begin{tabular}{|c|c|c|c|c|}
\hline Año & Gastos & Ejército & Burocracia & $\begin{array}{c}\text { Créditos } \\
\text { calificados }\end{array}$ \\
\hline 1826 & 2.807 .701 & 1.430 .360 & 237.453 & 915.642 \\
\hline 1827 & 2.516 .839 & 1.360 .014 & 400.700 & 282.226 \\
\hline 1828 & 2.573 .030 & 1.032 .907 & 428.930 & 365.361 \\
\hline 1829 & 1.816 .821 & 1.075 .721 & 335.857 & 385.533 \\
\hline 1830 & 1.809 .670 & 976.684 & 325.024 & 142.111 \\
\hline
\end{tabular}

Fuente: Elaboración propia a partir de los fondos documentales AGN, Fondo Republicano, Ministerio de Hacienda, H-4-1630, H-4-1637, H-4-1644 y H-4-1692.

La segunda mitad de la década de los veinte nos mostró una Tesorería General cuyas fortalezas descansaban en aduanas y consumos y unas Tesorerías departamentales que volvían a bombear fondos a Lima como resultado de la recuperación del tributo indígena. No obstante, la tendencia decreciente reveló la presencia de resistencias y profundas corrientes antifiscales. Años más tarde, Flora Tristán describió a una clase alta egoísta y con tendencias antisociales (Tristán, 2003 [1838]: 11). Era una forma de expresar la nula redistribución. Y las clases populares no cejarían en intentar esquivar en lo posible la presión fiscal. En cuanto a los gastos, la tendencia también apuntó al ajuste. Pero la persistencia de la atmósfera altamente militarizada mantuvo una estructura en la que sus- 
tancialmente los egresos de naturaleza militar no bajaron del $71 \%$. El Estado precisaba de una mínima operatividad que el Ejército garantizaba y su mantenimiento explicaba la relativa inelasticidad a la baja de su peso en el presupuesto nacional.

\section{A modo de balance}

El complejo proceso de transformación que experimentó el sistema fiscal en el Perú tuvo en el período comprendido entre la Independencia (1821) y la salida de Bolívar (1826) un momento clave de gestación. El paso de una hacienda coIonial a una estructura hacendística moderna y acorde con los tiempos económicos modernos fue endeble y dubitativo, lo cual afectó al proceso de construcción de la nueva nación. El marco general no ayudó. A un ciclo largo de guerras, que arrancaría en 1809 con las campañas del virrey Abascal por recuperar territorios perdidos y se extendería hasta 1826 con la capitulación de la fortaleza del Callao, y al que se añadiría una atmósfera militarizada en la que el conflicto fronterizo e interno formó parte de la cotidianidad económica y política de la nación, se sumaron unas élites disminuidas y un sector minero hundido en una atonía que derivó en recesión. Pero fue la interrelación entre los hechos económicos y políticos lo que fue perfilando un modelo fiscal que, a pesar de las iniciativas modernizadoras, acabó volteándose hacia el pasado.

A un protectorado que optó por un desarme fiscal, le siguió la puesta en marcha de iniciativas singulares, como fue el caso de la emisión de papel moneda, que chocaron con políticas incompatibles cuando desde el Gobierno se impusieron secuestros y expolios sobre el patrimonio de una parte sustancial de la élite comercial. El sistema hacendístico de la naciente República deambuló, falto de centralidad y privatizado en un alto grado, al borde de la quiebra hasta el final de la guerra. Solo los empréstitos extranjeros lograban mantener un mínimo pulso y la dinámica hizo aflorar un Estado en permanente fragilidad.

En 1825 todo quedaba por hacer y fue entonces cuando se abrió un tiempo de reformas, pero sobre una base disminuida. La caída de la riqueza nacional, como resultado de la desarticulación minera y comercial, y la destrucción de una buena parte de la élite capitalina, sin fácil reemplazo, que llevó aparejada una fuerte salida de capitales al exterior, comprometieron los planes de dinamización fiscal.

Aun así, la recomposición del Estado no era solo un problema político. Se necesitaba dinero para reforzar el destartalado aparato estatal. Un ejército en continuos problemas de abastecimiento y cobro de sueldos y una burocracia judicial y administrativa raquítica hacían inaplazable la consecución de rentas por parte de la Hacienda. Como la minería de la plata y los circuitos comerciales que la acompañaban eran solo un recuerdo de lo que fueron, las clases dirigentes se encontraban frente a un dilema que debían resolver si querían permanecer en su lugar. Si bien la racionalización de los ingresos por parte de una élite en pleno proceso de reconstrucción sobre la base de la propiedad territorial exigía un Estado fuerte que las hiciese posible, al mismo tiempo, dicho Estado reque- 
ría el numerario preciso con el que adquirir la consistencia mínima para poder afrontarla. Y esto último falló. La deuda pública y la confiscación a través de los secuestros fue el camino fácil para romper con el dilema. No obstante, una vez agotada la vía del endeudamiento, y tras el fracaso del experimento del papel moneda, la emisión masiva de cobre, los empréstitos nacionales y la suspensión del pago de la deuda externa en 1825, ya no quedaba otra opción que la de proceder a la ampliación de la base fiscal mediante la incorporación en el conjunto del sistema de la tributación directa sobre la renta y las propiedades.

En el primer semestre de 1826, junto con una profunda reorganización del Ministerio de Hacienda, el Estado liberal intentó vigorizarse a pesar de los recientes fracasos, titubeos y derrotas que habían plagado los años recientes. La propiedad moderna de la tierra, las desamortizaciones, una nueva fiscalidad y la protección arancelaria encaminada a sostener los ingresos terratenientes cerraban las líneas maestras de un proyecto de mínimos con el que asegurar la viabilidad institucional, económica y social de la nación. Sin embargo, las resistencias de unas clases dirigentes comprometidas en un proceso inacabado de reestructuración y recelosas de cualquier cesión hacia las nuevas autoridades replegaron al Estado.

El modelo fiscal quedó a medio camino entre la reforma y la tradición cuando fue necesario recuperar buena parte del andamiaje fiscal colonial, ante el escaso recorrido de la tributación directa y la limitada vitalidad de aduanas y consumos consecuencia de la profunda crisis minera. Y esta imperfecta gestación fue clave. Pronto empezaron a mostrarse los límites de la compleja recomposición del Estado y a los pobres resultados económicos y las decrecientes rendiciones fiscales que acaecieron entre 1826 y 1831, se sumó la profunda sima que significó el período de 1832-1845, con gobiernos sin presupuestos y tesorerías y prefecturas voluntariamente incomunicadas con el Ministerio de Hacienda, disimulando el silencio con inútiles informes parciales. Entonces, hubo que esperar a la etapa liberal de Ramón Castilla, en la década de los cincuenta, para, con bríos renovados, volver a pensar en una reforma de la Hacienda en mayúsculas. Pero eso es otra historia.

\section{Bibliografía}

AnNA, Timothy (2003). La caída del gobierno español en el Perú. El dilema de la independencia. Lima: Instituto de Estudios Peruanos.

Armas Asín, Fernando A. (2010). Patrimonio divino y capitalismo criollo. El proceso desamortizador de censos eclesiásticos en el Perú. Lima: Red para el Desarrollo de la Ciencias Sociales / Instituto Riva-Agüero - PUCP / Fundación M. J. Bustamante de la Fuente.

BRown, Kendall W. (2008). Borbones y aguardiente. La reforma imperial en el sur peruano. Lima: Banco Central de Reserva del Perú / Instituto de Estudios Peruanos.

Colección Documental de la Independencia del Perú (1973-1974). Primer Congreso Constituyente. Tomo xv, vols. 1 y 2. Lima: Comisión Nacional del Sesquicentenario de la Independencia del Perú. 
Colección Documental de la Independencia del Perú (1974). Obra de gobierno y epistolario de San Martín. Tomo XIII, vol. 1. Lima: Comisión Nacional del Sesquicentenario de la Independencia del Perú.

Colección Documental de la Independencia del Perú (1975). Obra gubernativa y epistolario de Bolívar. Tomo XIv, vols. 1 y 2. Lima: Comisión Nacional del Sesquicentenario de la Independencia del Perú.

CONTRERAS, Carlos (2001). "La transición fiscal de la colonia a la república». En: O'PHELAN, Scarlett (comp.). La independencia del Perú. De los Borbones a Bolívar. Lima: Fondo Editorial de la PUCP, págs. 197-235.

CONTRERAS, Carlos (2002). «La reforma fiscal de 1815: las finanzas peruanas en vísperas de la independencia». Revista Economía, Lima, xxv (50), págs. 123-148.

CONTRERAS, Carlos (2010). «Buenos para la guerra, malos para la paz: el legado económico de la independencia del Perú». En: BANDIERI, Susana (comp.). La historia económica y los procesos de independencia en la América hispana. Buenos Aires: Prometeo, págs. 269-298.

CONTRERAS, Carlos (2012). «El precio de ser libres: costos y consecuencias económicas de la independencia en el Perú». En: McEvor, Carmen; PALTI, Elías y NovoA, Mauricio (eds.). En el nudo del imperio. Independencia y democracia en el Perú. Lima: Instituto Francés de Estudios Andinos / Instituto de Estudios Peruanos, págs. 417441.

Córdova y URRUTIA, José María (1839). Estadística histórica, geográfica, industrial y comercial de los pueblos que componen las provincias del Departamento de Lima. Lima: Imprenta de Instrucción Primaria.

Dancuart, P. Emilio (1902). Anales de la hacienda pública del Perú. Tomo I. Lima: Imprenta Librería y Encuadernación de Guillermo Stolte.

DeustuA, José (2009). El embrujo de la plata. Lima: Banco Central de Reserva del Perú / Instituto de Estudios Peruanos.

ESPINOSA MONTERO, Álvaro (2001). «Oro, plata y mercurio, los nervios de la monarquía española». Revista de Historia Económica, Madrid, 3, págs. 503-538.

FISHER, John (2000). El Perú borbónico 1750-1824. Lima: Instituto de Estudios Peruanos.

Flores Galindo, Alberto (1991). La ciudad sumergida. Aristocracia y plebe (1760-1830). Lima: Editorial Horizonte.

Flores GuzMán, Ramiro A. (2010). «Fiscalidad y gastos de gobierno en el Perú Borbónico». En: Contreras, Carlos (ed.). Compendio de historia económica del Perú, Economía del período colonial tardío. Tomo III. Lima: Banco Central de Reserva del Perú e Instituto de Estudios Peruanos, págs. 295-376.

Gootenberg, Paul (1998). Imaginar el desarrollo. Las ideas económicas en el Perú postcolonial. Lima: Instituto de Estudios Peruanos.

Hamnett, Brian (2000). La política contrarrevolucionaria del virrey Abascal: Perú, 18061816. Lima: Instituto de Estudios Peruanos.

HARO, Dionisio de (2011). «La política monetaria de San Martín en el Perú». Revista de Indias, Madrid, LXXI, págs. 793-823.

HARO, Dionisio de (2014). «De virreinato a nación: quiebra colonial y Estado sin Hacienda en el Perú». En: MARTínez RiAZA, Ascensión (ed.). La independencia inconcebible. España y la «pérdida» del Perú (1820-1824). Lima: Fondo Editorial de la PUCP / Instituto Riva-Agüero, págs. 287-344. 
HARO, Dionisio de (2017). «La independencia sobre caminos de papel: el Banco Auxiliar del Perú (1822)». En: MARICHAL, Carlos y GamBI, Thiago (eds. lits.). Historia bancaria y monetaria de América Latina (siglos XIX y XX): nuevas perspectivas. Santander: Editorial de la Universidad de Cantabria / Universidade Federal de Alfenas, págs. 27-62.

HARO, Dionisio de (2019). «Para ganar la guerra: el Padrón General de Contribuyentes de Lima (1821) y la política liberal del virrey La Serna». Revista de Indias, Madrid, LXXIX (275), págs. 197-233.

IRIGOIN, Alejandra (2016). «Representation without taxation, taxation without consent: the legalicy of Spanish colonialism in America». Revista de Historia Económica, Madrid, XXXIV (2), págs. 169-208.

IRIGOIN, Alejandra y GRAFE, Regina (2008). «Bargaining for absolutism: a Spanish path to Nation-State and Empire building». Hispanic American Historical Review, Durham, 88 (2), págs. 173-209.

KUETHE, Allan J. y ANDRIEN, Kenneth J. (2014). The Spanish Atlantic world in the eighteenth century. War and Bourbon reforms, 1713-1796. Nueva York: Cambridge University Press.

Leguía y Martínez, Germán (1972). Historia de la emancipación del Perú: El Protectorado. 7 vols. Lima: Publicaciones de la Comisión Nacional del Sesquicentenario de la Independencia del Perú.

LYNCH, John (2006). Simón Bolívar. Barcelona: Crítica.

MARICHAL, Carlos (1999). La bancarrota del virreinato. Nueva España y las finanzas del imperio español, 1780-1810. México: Fondo de Cultura Económica.

MÉnDEZ, Cecilia (2014). La república plebeya. Huanta y la formación del Estado peruano, 1820-1850. Lima: Instituto de Estudios Peruanos.

PalAcios Moreyra, Carlos (1983). La deuda angloperuana, 1822-1890. Lima: Studium.

PANIAGUA, Valentín (2007). «El proceso constituyente y la Constitución vitalicia (bolivariana) de 1826». Historia Constitucional, Madrid, 8, págs. 67-94.

Peralta Ruiz, Víctor y Haro, Dionisio de (eds.) (2019). España en Perú (1796-1824). Ensayos sobre los últimos gobiernos virreinales. Madrid: Universidad Michoacana de San Nicolás de Hidalgo y Marcial Pons.

Prados De La Escosura, Leandro y AmAral, Samuel (eds.) (1993). La independencia americana: consecuencias económicas. Madrid: Alianza.

QUIROZ, Alfonso (1993). Deudas olvidadas. Instrumentos de crédito en la economía colonial peruana 1750-1820. Lima: Pontificia Universidad Católica del Perú.

Quiroz, Alfonso (2014). Historia de la corrupción en el Perú. Lima: Instituto de Estudios Peruanos.

RoJAs, Rolando (2019). «Las bases fiscales del Perú poscolonial, 1821-1845». Investigaciones Sociales, Lima, 22, 40, págs. 159-177.

SALINAS, Alejandro (2011). «Las finanzas públicas entre 1821-1930». En: ConTRERAS, Carlos (ed.). Compendio de historia económica del Perú, Economía de la primera centuria independiente. Tomo Iv. Lima: Banco Central de Reserva del Perú / Instituto de Estudios Peruanos, págs. 369-375.

Selden Rose, Robert (1916). «The "España defendida” by Don Francisco de Quevedo». Boletín de la Real Academia de la Historia, Madrid, 69, págs. 140-182.

SUMmERHILL, William R. (2008). «Fiscal bargains, political institutions, and economic performance». Hispanic American Historical Review, Durham, 88, 2, págs. 219-233. 
TePASKE, John J. y Brown, Kendall W. (eds.) (2010). A new world of gold and silver. Leiden: Brill.

Tristán, Flora (2003 [1838]). Peregrinaciones de una paria. Arequipa: El Lector.

VIzCARRA, Catalina (2011). «Guano, compromisos creíbles y el pago de la deuda externa peruana del siglo XIX». Economía, Lima, XXXIV (67), págs. 9-39.

Fecha de recepción: 28 de mayo de 2021

Fecha de aceptación: 11 de agosto de 2021

Fecha de publicación: 22 de diciembre de 2021 